\title{
Undertreatment of human immunodeficiency virus in psychiatric inpatients: a cross-sectional study of seroprevalence and associated factors
}

This article was published in the following Dove Press journal:

Neuropsychiatric Disease and Treatment

II June 2015

Number of times this article has been viewed

Miguel Angel Gonzalez-

Torres $^{1,2}$

Miguel Angel Salazar ${ }^{3}$

Manuel Imaz ${ }^{4}$

Lucía Inchausti ${ }^{1,2}$

Berta lbañez ${ }^{5}$

Aranzazu Fernandez-Rivas 1,2

Javier Pastor ${ }^{3}$

Bosco Anguiano ${ }^{3}$

Pedro Muñoz ${ }^{3}$

Eduardo Ruiz ${ }^{1,2}$

Rodrigo Oraa ${ }^{3}$

Sonia Bustamante ${ }^{1,2}$

Sofia Alvarez de Eulate ${ }^{2}$

Ramón Cisterna ${ }^{4,6}$

'Department of Neuroscience, University of the Basque Country,

${ }^{2}$ Psychiatry Service, Basurto

University Hospital, Bilbao, ${ }^{3}$ Mental

Health Network of Biscay, Basque

Health Service, Biscay, ${ }^{4}$ Microbiology

Service, Basurto University Hospital,

Bilbao, ${ }^{5}$ Navarra Biomed-Miguel Servet

Foundation, Red de Investigación en

Servicios Sanitarios y Enfermedades

Crónicas (REDISSEC), Pamplona,

${ }^{6}$ Department of Microbiology,

University of the Basque Country,

Bilbao, Spain

Correspondence: Miguel Angel

Gonzalez-Torres

Psychiatry Service, Basurto University

Hospital, Avenida de Montevideo 18,

Bilbao 48013, Spain

Tel +34944006066

$\mathrm{Fax}+34944006213$

Email miguelangel.gonzaleztorres@

osakidetza.net
Background: The aims of this study were to evaluate the prevalence of HIV and its associated demographic and clinical factors among psychiatric inpatients of a general hospital.

Methods: This was a single-center, observational, cross-sectional study that included patients consecutively admitted to our unit aged 16 years or older and with no relevant cognitive problems. The patients were evaluated using a semistructured interview and an appropriate test for HIV infection.

Results: Of the 637 patients who were screened, 546 (86\%) who consented to participate were included in the analyses. Twenty-five $(4.6 \%, 95 \%$ confidence interval [CI] 3.0-6.8) patients were HIV-positive. The prevalence was higher among patients with substance misuse $(17.4 \%$, 95\% CI 9.7-28.8). All except one of the 25 patients knew of their seropositive condition prior to participation in the study. Only 14 (56\%) of the 25 seropositive patients had previously received pharmacological treatment for their infection. According to the multiple logistic regression analysis, the likelihood of HIV infection was lower in patients with higher levels of education and higher among patients who were single, had history of intravenous drug use, and had an HIV-positive partner, particularly if they did not use condoms. Among the patients with HIV infection, 18 (72\%) had a history of suicide attempts compared with $181(34.7 \%)$ of the patients without HIV infection (relative risk 2.1, 95\% CI 1.6-2.7; $P<0.001$ ).

Conclusion: HIV infection is highly prevalent in patients admitted to a psychiatric unit, especially those with a diagnosis of substance misuse. Seropositive patients show very poor treatment adherence. The risk of suicide seems to be very high in this population. Implementing interventions to reduce the suicide risk and improve adherence to antiretroviral therapy and psychotropic medications seems crucial.

Keywords: severe mental illness, human immunodeficiency virus, adherence, epidemiology

\section{Introduction}

Patients with severe mental illness are at a higher risk for developing HIV infection than those without a mental illness. ${ }^{1,2}$ Factors associated with this increased risk include the following: psychiatric symptoms, such as cognitive impairment, which may lessen the ability for self-care; ${ }^{3}$ treating these patients as asexual and, therefore, not providing them with adequate sexual education; ${ }^{4}$ lack of social support; ${ }^{5}$ lack of planning or inadequate risk assessment; ${ }^{6}$ and unfavorable economic conditions. ${ }^{7,8}$ Each of these factors is associated with risky sexual behaviors.

Although variable across studies, the self-reported prevalence of HIV risk behaviors is high among patients with severe mental illness, ${ }^{1}$ including multiple partners (57\%), lack of condom use (46\%), injectable drug use (22\%), and 
needle-sharing (61\%). Similarly, the prevalence of HIV infection among psychiatric patients varies across studies, with some reporting a prevalence of approximately $1 \%$ and others close to $5 \% .^{2}$ Additionally, these prevalence studies have several limitations. The majority of the studies have been conducted in the USA or developing countries, ${ }^{2}$ and most of them have comprised patients with schizophrenia or bipolar disorder.

The aims of our present study were as follows: to evaluate the prevalence of HIV infection among inpatients in a psychiatric unit of a general hospital, both overall and by psychiatric diagnoses; to investigate the association between the presence of HIV infection and demographic and clinical characteristics, such as risk behaviors; and to evaluate the utility of systematic screening by enzyme immunoassay analysis for HIV patients admitted to an inpatient psychiatric unit.

\section{Materials and methods}

This was a single-center, observational, cross-sectional study conducted in a psychiatric unit in a large urban area $(235,000$ inhabitants) in the Basque Country of Spain. We included patients consecutively admitted to our unit if they were 16 years or older. Patients were excluded if they had a low intelligence quotient, exhibited relevant cognitive problems, or had been previously admitted to the unit during the study period. Recruitment lasted for 3 years.

The study was reviewed and approved by the ethics committee of the Hospital Universitario de Basurto, Bilbao, Spain, and conducted in accordance with the principles of the Declaration of Helsinki. All of the patients gave their written informed consent prior to participating in the study.

\section{Procedures}

The patients were evaluated using a semistructured interview developed ad hoc by the authors. The interview was performed once the patient was judged by the investigator to be clinically stable and included the following information: demographic and clinical data, personal and family history of HIV infection (if positive, treatments received for HIV), and HIV risk factors, including sexual practices. All psychiatric disorders were diagnosed by the treating psychiatrist, codified according to the ICD-10 (International Classification of Diseases, Tenth Revision), ${ }^{9}$ and reviewed by at least one other psychiatrist from the research team. Any disagreement was resolved by consensus. Pre-test and post-test counseling regarding HIV education, prevention, and treatment were implemented.
Blood samples for routine analyses were systematically extracted from all of the patients admitted to the unit, and a small blood sample was kept aside for subsequent enzyme immunoassay analysis. These latter samples were sent to the serology unit at the microbiology department and stored. Once written informed consent was obtained, the serology unit was notified and the enzyme immunoassay analysis test for HIV infection was performed. Standard HIV antibody tests were performed (ie, enzyme-linked immunosorbent assay and confirmatory Western blot). If the patient refused to participate, the serology unit was immediately notified, and the corresponding blood sample was destroyed.

\section{Statistical analysis}

All of the recruited patients were included in the analyses. Due to the asymmetry of their distribution, the demographic and clinical characteristics are presented as medians and interquartile ranges for age, and the categorical variables are presented as frequencies and percentages.

The point estimate of the prevalence of HIV infection and the corresponding 95\% confidence interval (CI) were calculated for the overall sample and for each psychiatric diagnostic group using a sampling distribution of the sample proportion with a Yates correction.

The relationship between the presence of HIV infection and the demographic and clinical characteristics was first examined with a bivariate analysis. Pearson chi-squared or Fisher's exact tests were used for comparing the categorical variables, and a Mann-Whitney $U$-test was used to compare age. Second, a stepwise multivariate logistic regression analysis was performed, including the variables that were statistically significant in the bivariate analysis as explanatory factors and the presence of HIV infection as the dependent variable. The model's predictive capability was evaluated by calculating the area under the receiver operating characteristic curve. All of the analyses were performed using the free software R 2.5.1. ${ }^{10}$

\section{Results}

\section{Patient disposition and description}

A total of 637 patients who were screened during the study period met the selection criteria. Ninety-one (14\%) did not give written informed consent, leaving 546 patients in the analysis. The patients had a median age of 38 (interquartile range 30-51) years, and males were slightly predominant $(n=306,56 \%)$. The remaining demographic characteristics and the distribution of HIV risk behaviors are presented in Table 1. The most frequent psychiatric 
Table I Sociodemographic characteristics and risk factors for the overall sample and by HIV infection status

\begin{tabular}{|c|c|c|c|c|c|}
\hline & $\begin{array}{l}\text { Total } \\
(n=546)\end{array}$ & $\begin{array}{l}\text { Not HIV } \\
(n=52 I)\end{array}$ & $\begin{array}{l}\text { HIV } \\
(n=25)\end{array}$ & Test & $P$-value \\
\hline Age, years* & $38(30-5 I)$ & $39(30-5 I)$ & $32(30-34)$ & $U=8.988$ & 0.001 \\
\hline \multicolumn{6}{|l|}{ Sex } \\
\hline Male & $306(56 \%)$ & $292(56 \%)$ & $14(56 \%)$ & \multirow[t]{2}{*}{$\chi^{2}=0.041$} & \multirow[t]{2}{*}{0.840} \\
\hline Female & $240(44 \%)$ & 229 (44\%) & II (44\%) & & \\
\hline \multicolumn{6}{|l|}{ Education } \\
\hline No studies & $7 \mid(13 \%)$ & $62(12 \%)$ & $9(36 \%)$ & \multirow[t]{3}{*}{$F$} & \multirow[t]{3}{*}{0.003} \\
\hline Nonuniversity studies & $426(78 \%)$ & $410(79 \%)$ & $16(64 \%)$ & & \\
\hline University studies & $49(9 \%)$ & $49(9 \%)$ & $0(0 \%)$ & & \\
\hline \multicolumn{6}{|l|}{ Employment status } \\
\hline Employed & $124(23 \%)$ & $119(23 \%)$ & $5(33 \%)$ & & \\
\hline Others (eg, retired, homemaker) & $180(33 \%)$ & 177 (22\%) & $3(20 \%)$ & \multirow[t]{2}{*}{$\chi^{2}=6.892$} & \multirow[t]{2}{*}{0.032} \\
\hline Unemployed & $242(44 \%)$ & $225(43 \%)$ & $17(47 \%)$ & & \\
\hline \multicolumn{6}{|l|}{ Marital status } \\
\hline Married & $142(26 \%)$ & $|4|(27 \%)$ & $\mathrm{I}(4 \%)$ & & \\
\hline Separated & $97(18 \%)$ & 97 (19\%) & $0(0 \%)$ & \multirow[t]{3}{*}{$F$} & \multirow[t]{3}{*}{$<0.001$} \\
\hline Single & $283(52 \%)$ & $260(50 \%)$ & $23(92 \%)$ & & \\
\hline Widowed & $24(4 \%)$ & $23(4 \%)$ & $\mathrm{I}(4 \%)$ & & \\
\hline \multicolumn{6}{|l|}{ Living arrangements } \\
\hline Couple & $162(30 \%)$ & $158(30 \%)$ & $4(16 \%)$ & & \\
\hline With parents & $20 \mathrm{I}(37 \%)$ & $192(37 \%)$ & $9(36 \%)$ & \multirow[t]{4}{*}{$F$} & \multirow[t]{4}{*}{0.030} \\
\hline Alone & $142(26 \%)$ & $136(26 \%)$ & $6(24 \%)$ & & \\
\hline Homeless & $13(2 \%)$ & II (2\%) & $2(8 \%)$ & & \\
\hline Others & $28(5 \%)$ & $24(5 \%)$ & $4(16 \%)$ & & \\
\hline \multicolumn{6}{|l|}{ IV drug use } \\
\hline No & $49 \mathrm{I}(90 \%)$ & $49 \mathrm{I}(94 \%)$ & $0(0 \%)$ & \multirow[t]{2}{*}{$F$} & \multirow[t]{2}{*}{$<0.001$} \\
\hline Yes & $55(10 \%)$ & $30(6 \%)$ & $25(100 \%)$ & & \\
\hline \multicolumn{6}{|l|}{ Other drug use } \\
\hline No & 135 (25\%) & 135 (25\%) & $0(0 \%)$ & \multirow[t]{2}{*}{$\chi^{2}=7.270$} & 0.007 \\
\hline Yes & $4 I I(75 \%)$ & 386 (75\%) & $25(100 \%)$ & & \\
\hline Tattoos & & & & & \\
\hline No & $484(89 \%)$ & 475 (9l\%) & $9(36 \%)$ & $F$ & $<0.001$ \\
\hline Yes & $62(11 \%)$ & $46(9 \%)$ & $16(64 \%)$ & & \\
\hline Heterosexual relationships & & & & & \\
\hline Never & $72(13 \%)$ & 71 (14\%) & $\mathrm{I}(4 \%)$ & & \\
\hline Use condom (always or usually) & 249 (46\%) & 237 (45\%) & $12(48 \%)$ & $F$ & 0.367 \\
\hline Never condom & $225(41 \%)$ & $213(41 \%)$ & $12(48 \%)$ & & \\
\hline Homosexual relationships & & & & & \\
\hline Never & 498 (91\%) & 477 (92\%) & 21 (84\%) & & \\
\hline Use condom & $18(3 \%)$ & $17(3 \%)$ & I (4\%) & $F$ & 0.217 \\
\hline Never condom & $30(6 \%)$ & $27(5 \%)$ & $3(12 \%)$ & & \\
\hline PDU partner & & & & & \\
\hline Never & 493 (90\%) & 487 (93\%) & $6(24 \%)$ & & \\
\hline Use condom & $28(5 \%)$ & $21(4 \%)$ & 7 (28\%) & $F$ & $<0.001$ \\
\hline Never condom & $25(5 \%)$ & $13(3 \%)$ & $12(48 \%)$ & & \\
\hline HIV partner & & & & & \\
\hline Never & 507 (93\%) & 499 (96\%) & $8(32 \%)$ & & \\
\hline Use condom & $21(4 \%)$ & $14(3 \%)$ & $7(28 \%)$ & $F$ & $<0.001$ \\
\hline Never condom & $18(3 \%)$ & $8(1 \%)$ & $10(40 \%)$ & & \\
\hline Prostitution & & & & & \\
\hline Never & 391 (72\%) & 377 (72\%) & 14 (56\%) & & \\
\hline Use condom & II (20\%) & 105 (20\%) & 7 (28\%) & $F$ & 0.113 \\
\hline Never condom & $43(8 \%)$ & $39(8 \%)$ & $4(16 \%)$ & & \\
\hline
\end{tabular}

Note: *All variables are summarized with frequencies and percentages, except age, for which the median and interquartile ranges are given. Abbreviations: PDU, parenteral drug user; IV, intravenous; U, Mann-Whitney U-test; $\chi^{2}$, Pearson chi-squared test; $F$, Fisher's exact test. 
Table 2 Prevalence of HIV by psychiatric diagnosis

\begin{tabular}{llll}
\hline Diagnosis & $\mathbf{n}$ & \multicolumn{2}{l}{ Prevalence } \\
\cline { 3 - 4 } & & $\begin{array}{l}\text { Point } \\
\text { estimate }\end{array}$ & $\mathbf{9 5 \%} \mathbf{~ C l}$ \\
\hline Nonaffective psychoses & 235 & $2.1 \%$ & $0.8-5.2$ \\
Mood disorders & 129 & $1.6 \%$ & $0.3-6.1$ \\
Substance misuse & 69 & $17.4 \%$ & $9.7-28.8$ \\
Personality disorders & 50 & $6.0 \%$ & $1.6-17.5$ \\
Neuroses and adjustment & 46 & $2.2 \%$ & $0.1-13.0$ \\
disorders & & & \\
Organic disorders & 17 & $11.8 \%$ & $2.1-37.8$ \\
\hline Abbrevation:
\end{tabular}

Abbreviation: $\mathrm{Cl}$, confidence interval.

diagnoses (Table 2 ) were nonaffective psychoses $(n=235$, $43 \%)$ and mood disorders ( $\mathrm{n}=129,24 \%)$ substance misuse $(\mathrm{n}=69,13 \%)$, personality disorders $(\mathrm{n}=50,9 \%)$, neuroses and adjustment disorders $(n=46,8 \%)$, and organic disorders $(n=17,3 \%)$.

\section{Prevalence of HIV infection and associated factors}

Twenty-five $(4.6 \%, 95 \%$ CI 3.0-6.8) patients were HIVpositive according to the enzyme-linked immunosorbent assay test, and all of them were confirmed by the Western blot test. The test for HIV-2 was negative in all of the patients. With the exception of one patient, all 25 patients knew their seropositive condition prior to study participation; $92 \%$ knew of their condition at least 6 months prior to entering the study. The prevalence of HIV infection was much higher in patients with substance misuse $(17.4 \%, 95 \%$ CI 9.7-28.8) relative to any other psychiatric diagnosis (Table 2). Among the patients with HIV infection, 18 (72\%) had a history of suicide attempts compared with 181 (34.7\%) patients without HIV infection (relative risk 2.1, 95\% CI $1.6-2.7 ; P<0.001)$. Only 14 (56\%) of the 25 seropositive patients had previously received pharmacological treatment for their infection.

In the bivariate analysis (Table 1), the following demographic characteristics were significantly associated with the presence of HIV infection: age, level of education, employment status, marital status, and living arrangements. Regarding HIV risk behaviors, the following were found to be significant in the bivariate analysis: intravenous drug use, other drug use, tattoos, a parenteral drug-using partner, lack of condom use, and having an HIV-positive partner and never using condoms.

In the multivariate logistic regression model, the likelihood of HIV infection was lower among patients with higher levels of education (nonuniversity studies odds ratio [OR]
$0.27,95 \%$ CI 0.11-0.63; university studies OR 0, 95\% CI 0 to infinity). The likelihood was highest in patients who were single (OR 9.9, 95\% CI 0 94-105), patients with a history of intravenous drug use (OR not calculable, $95 \% \mathrm{CI} 0$ to infinity), and patients who had an HIV-positive partner, especially if they did not use condoms (OR 10.91, 95\% CI 1.57-75.59) but also if they used condoms (OR 6.16,95\% CI 1.08-35.29). Patients with tattoos also showed a nonsignificant increased risk of HIV infection (OR 3.6, 95\% CI 0.78-16.73). This model had a very high predictive capability, with an area under the receiver operating characteristic curve of 0.993 . Patients who had a partner with a history of intravenous drug use also showed a significant association in the bivariate analysis, but it was not included in the multivariate model because it showed a strong association with a history of having an HIV-positive partner.

\section{Discussion}

The prevalence of HIV infection among patients admitted to a psychiatric unit is high (4.6\%) and is especially associated with a history of intravenous drug use. These prevalence results are consistent with several studies conducted in the USA, ${ }^{711-13}$ and most of the studies conducted in Europe, ${ }^{14-16}$ which report figures close to $5 \%$. By contrast, some large studies conducted in the USA reported a much lower prevalence of $1 \% ;{ }^{17,18}$ however, these studies elicited HIV infection status through a chart review. In a similar setting to our study, Fernández-Egea et al reported a prevalence of $1.4 \%$ among 332 psychiatric inpatients admitted to another psychiatric unit in Spain. ${ }^{19}$ It is important to note that this latter study was retrospective and only evaluated patients who had requested the serological test (ie, $65 \%$ of the patients in their study). More importantly, only $1.8 \%$ of the patients in that study had a history of intravenous drug use compared with $10 \%$ in our sample. A review of these studies can be found elsewhere. ${ }^{2}$

The single most important factor associated with the presence of HIV infection in our sample was a history of intravenous drug use. In fact, all 25 HIV patients in our sample had a history of intravenous drug use compared with only $6 \%$ of the 521 patients without HIV infection. Moreover, the highest prevalence of HIV infection was found in patients with substance misuse (17\%), followed by patients with personality disorders $(6 \%)$. Some authors use the term "triple diagnosis" to refer to this especially vulnerable subpopulation of patients who have HIV infection, a chronic mental illness, and substance abuse. ${ }^{20-22}$ Patients with a triple diagnosis are less likely to receive treatment for their 
mental illness or for their substance abuse disorder. ${ }^{23}$ In addition, the co-occurrence of the three diagnoses is associated with decreased receipt of highly active antiretroviral therapy (HAART) and viral suppression, ${ }^{24}$ and decreased adherence to treatment. ${ }^{25,26}$ Our results support these concerns. Only 14 of the $25(56 \%)$ HIV-infected patients received antiretroviral therapy, even though most of these patients had been identified as HIV-positive more than 6 months prior to the study and 12 patients had been HIV-positive for over 7 years. Therefore, it has been suggested that an integrative approach combining HIV, substance abuse, and mental health treatment might improve outcomes in this population. ${ }^{24,26}$ Unfortunately, the results from The HIV/AIDS Treatment Adherence, Health Outcomes and Cost Study, which evaluated the cost-effectiveness of integrated HIV primary care, mental health, and substance abuse services among triply diagnosed patients, have been somewhat disappointing. ${ }^{27}$ In this randomized clinical trial, there were no differences between the integrative approach and usual care regarding annual health services costs and quality of life outcomes. ${ }^{27}$

The importance of the triple diagnosis is not limited to its impact on treatment for the different conditions in these patients. Although our sample of patients with a triple diagnosis was small, our results show that this population seems to have an even higher suicide risk than those only diagnosed with HIV. The risk of suicide in HIV patients is already high. A recent review reported that $20 \%$ of HIV-positive people had deliberately harmed themselves. ${ }^{28}$ This figure is much lower than the $72 \%$ of HIV-infected patients who reported a previous suicide attempt in our study, which represents a twofold increase in the number of suicide attempts compared with psychiatric inpatients without HIV infection.

Our results do not support systematic screening for HIV infection among patients admitted to a psychiatric inpatient unit. Among the 25 patients with HIV infection, only one was a new case. Our results are possibly explained by the fact that patients who have a history of intravenous drug use are more likely to be tested for HIV ${ }^{29}$ Therefore, it seems that focusing on patients with risky behaviors may be a more efficient procedure when screening for HIV infection among psychiatric patients. However, it should be noted that a substantial proportion of patients $(14 \%)$ admitted to our unit during the study period refused to participate in the study. Because the study only comprised a psychiatric interview and HIV testing, it is likely that most of these patients refused study participation because of the HIV testing. Among the general population, reasons for refusing HIV testing include having been tested before, believing they are not at risk for contracting HIV, fearing the results, and fearing stigmatization. ${ }^{29}$ Although much less is known about HIV testing in psychiatric patients, reports indicate it is associated with advanced education, age younger than 40 years, living alone, the presence of other medical conditions, a history of sexually transmitted diseases, sexual abuse, and inconsistent lifetime condom use. ${ }^{30}$ Unfortunately, we cannot rule out that we might have found a higher proportion of new HIV-seropositive cases among the $14 \%$ of patients who did not consent to participate in the study. This finding highlights the need for HIV counseling to reduce the number of patients declining to be tested for HIV infection.

Our study has several limitations. Because we used a cross-sectional design, the associations we found cannot necessarily be considered causal. The study was conducted in a single psychiatric unit, thus limiting the generalizability of our results. Data regarding specific HAART recommended and laboratory variables, such as viral load and current CD4, were not included in the study. Cognitive ability was assessed by clinical impression and not with a specific instrument. Finally, we used an ad hoc, semistructured interview to determine a psychiatric diagnosis that was based on the investigator's judgment and consensus with another psychiatrist. Despite these limitations, our results show that HIV infection is highly prevalent among patients admitted to a psychiatric unit, especially those with a diagnosis of substance misuse, and the risk of suicide seems very high in this population. Unfortunately, identifying these patients through an HIV screening test seems inefficient at this level of care. However, recognizing that this group has poor treatment adherence and is at high risk for suicide might be crucial for implementing interventions to reduce suicide risk and improve adherence to antiretroviral therapy and psychotropic medications. Equally important is implementing sexual risk reduction programs among those who are HIV-negative to reduce the risk of becoming seropositive.

\section{Acknowledgments}

This project was undertaken with the support of grants from the FIS Agency of the Spanish Ministry of Health and Basurto Hospital Research Commission. The authors regret to advise of the passing of María J Carvajal prior to publication of this paper.

\section{Disclosure}

The authors report no conflicts of interest in this work. 


\section{References}

1. Meade CS, Sikkema KJ. HIV risk behavior among adults with severe mental illness: a systematic review. Clin Psychol Rev. 2005;25(4): 433-457.

2. Campos LN, Guimaraes MD, Carmo RA, et al. HIV, syphilis, and hepatitis $\mathrm{B}$ and $\mathrm{C}$ prevalence among patients with mental illness: a review of the literature. Cad Saude Publica. 2008;24 Suppl 4:s607-s620.

3. Carmen E, Brady SM. AIDS risk and prevention for the chronic mentally ill. Hosp Community Psychiatry. 1990;41(6):652-657.

4. Gonzalez-Torres MA, Salazar MA, Inchausti L, et al. Lifetime sexual behavior of psychiatric inpatients. J Sex Med. 2010;7(9): 3045-3056.

5. Randolph ME, Pinkerton SD, Somlai AM, et al. Severely mentally ill women's HIV risk: the influence of social support, substance use, and contextual risk factors. Community Ment Health J. 2007;43(1):33-47.

6. Gordon CM, Carey MP, Carey KB, Maisto SA, Weinhardt LS. Understanding HIV-related risk among persons with a severe and persistent mental illness: insights from qualitative inquiry. $J$ Nerv Ment Dis. 1999;187(4):208-216.

7. Stewart DL, Zuckerman CJ, Ingle JM. HIV seroprevalence in a chronically mentally ill population. J Natl Med Assoc. 1994;86(7): 519-523.

8. McKinnon K, Cournos F, Herman R. HIV among people with chronic mental illness. Psychiatr Q. 2002;73(1):17-31.

9. World Health Organization. The ICD-10 Classification of Mental and Behavioural Disorders: clinical descriptions and diagnosis guidelines. Geneva, Switzerland: World Health Organization; 1993. Available from: http:/www.who.int/classifications/icd/en/GRNBOOK.pdf. Accessed March 16, 2015.

10. R Development Core Team. A Language and Environment for Statistical Computing. Vienna, Austria: R Foundation for Statistical Computing; 2007.

11. Klinkenberg WD, Caslyn RJ, Morse GA, et al. Prevalence of human immunodeficiency virus, hepatitis $\mathrm{B}$, and hepatitis $\mathrm{C}$ among homeless persons with co-occurring severe mental illness and substance use disorders. Compr Psychiatry. 2003;44(4):293-302.

12. Cournos F, Horwath E, Guido JR, McKinnon K, Hopkins N. HIV-1 infection at two public psychiatric hospitals in New York City. AIDS Care. 1994;6(4):443-452.

13. Schwartz-Watts D, Montgomery LD, Morgan DW. Seroprevalence of human immunodeficiency virus among inpatient pretrial detainees. Bull Am Acad Psychiatry Law. 1995;23(2):285-288.

14. Zamperetti M, Goldwurm GF, Abbate E, Gris T, Muratori S, Vigo B. Attempted suicide and HIV infection: epidemiological aspects in a psychiatric ward. Int Conf AIDS. 1990;6:182.

15. Naber D, Pajonk FG, Perro C, Lohmer B. Human immunodeficiency virus antibody test and seroprevalence in psychiatric patients. Acta Psychiatr Scand. 1994;89(5):358-361.
16. Ayuso-Mateos JL, Montanes F, Lastra I, Picazo de la Garza J, AyusoGutierrez JL. HIV infection in psychiatric patients: an unlinked anonymous study. Br J Psychiatry. 1997;170:181-185.

17. Himelhoch S, McCarthy JF, Ganoczy D, Medoff D, Dixon LB, Blow FC. Understanding associations between serious mental illness and HIV among patients in the VA Health System. Psychiatr Serv. 2007;58(9):1165-1172.

18. Beyer JL, Taylor L, Gersing KR, Krishnan KR. Prevalence of HIV infection in a general psychiatric outpatient population. Psychosomatics. 2007;48(1):31-37.

19. Fernández-Egea, Gomez Gil E, Corbella Santoma B, Salamero Baro M, Blanch Andreu J, Valdes Miyar M. [Serological testing and prevalence of human immunodeficiency, hepatitis $\mathrm{B}$ and $\mathrm{C}$ viruses infections amongst acute psychiatric inpatients]. Med Clin (Barc). 2002;119(18):690-692. Spanish.

20. Batki SL. Drug abuse, psychiatric disorders, and AIDS. Dual and triple diagnosis. West J Med. 1990;152(5):547-552.

21. Douaihy AB, Jou RJ, Gorske T, Salloum IM. Triple diagnosis: dual diagnosis and HIV disease, part 2. AIDS Read. 2003;13(8):375-382.

22. Douaihy AB, Jou RJ, Gorske T, Salloum IM. Triple diagnosis: dual diagnosis and HIV disease, Part 1. AIDS Read. 2003;13(7):331-332, 339-341.

23. Weaver MR, Conover CJ, Proescholdbell RJ, Arno PS, Ang A, Ettner SL. Utilization of mental health and substance abuse care for people living with HIV/AIDS, chronic mental illness, and substance abuse disorders. J Acquir Immune Defic Syndr. 2008;47(4):449-458.

24. Chander G, Himelhoch S, Fleishman JA, et al. HAART receipt and viral suppression among HIV-infected patients with co-occurring mental illness and illicit drug use. AIDS Care. 2009;21(5):655-663.

25. Mellins CA, Havens JF, McDonnell C, et al. Adherence to antiretroviral medications and medical care in HIV-infected adults diagnosed with mental and substance abuse disorders. AIDS Care. 2009;21(2):168-177.

26. Lee S, Rothbard AB, Noll E, Blank MB. Use of HIV and psychotropic medications among persons with serious mental illness and HIV/AIDS. Adm Policy Ment Health. 2011;38(5):335-344.

27. Weaver MR, Conover CJ, Proescholdbell RJ, et al. Cost-effectiveness analysis of integrated care for people with HIV, chronic mental illness and substance abuse disorders. J Ment Health Policy Econ. 2009;12(1):33-46.

28. Catalan J, Harding R, Sibley E, Clucas C, Croome N, Sherr L. HIV infection and mental health: suicidal behavior - systematic review. Psychol Health Med. 2011;16(5):588-611.

29. Senn TE, Carey MP. HIV testing among individuals with a severe mental illness: review, suggestions for research, and clinical implications. Psychol Med. 2009;39(3):355-363.

30. Souto Melo AP, Machado CJ, Crosland Guimaraes MD. HIV testing in psychiatric patients in Brazil. J Acquir Immune Defic Syndr. 2011; 57 Suppl 3:S157-S163.
Neuropsychiatric Disease and Treatment

\section{Publish your work in this journal}

Neuropsychiatric Disease and Treatment is an international, peerreviewed journal of clinical therapeutics and pharmacology focusing on concise rapid reporting of clinical or pre-clinical studies on a range of neuropsychiatric and neurological disorders. This journal is indexed on PubMed Central, the 'PsycINFO' database and CAS,
Dovepress

and is the official journal of The International Neuropsychiatric Association (INA). The manuscript management system is completely online and includes a very quick and fair peer-review system, which is all easy to use. Visit http://www.dovepress.com/testimonials.php to read real quotes from published authors. 